\title{
A DISCRICIONARIEDADE DA BUROCRACIA DE RUA: OUTRA ANÁLISE SOBRE O SEU PAPEL NA IMPLEMENTAÇÃO DA POLÍTICA DE SAÚDE PARA A POPULAÇÃO NEGRA EM SALVADOR - BA
}

\author{
THE DISCRETION OF STREET-LEVEL BUREAUCRACY: \\ A DIFFERENT ANALYSIS ON ITS ROLE IN HEALTHCARE POLICY \\ IMPLEMENTATION FOR THE BLACK POPULATION OF SALVADOR-BA
}

\begin{abstract}
Resumo
Este artigo tem por objetivo analisar como se deu o processo de implementação da Política de Saúde para a População Negra na cidade de Salvador, Bahia, entre 2005 e 2012. Para isso, considerou-se como categorias analíticas o racismo institucional, o papel da burocracia de rua e a sua discricionariedade, os recursos que foram utilizados durante a implementação da política. Para que esse processo fosse realizado, uma Rede de pontos focais foi formada com burocratas de rua que atuam nas instituições de saúde, com o objetivo de executar os parâmetros formulados para a política em questão. Dialogou-se com duas abordagens referenciadas para dar conta dos achados resultantes da pesquisa: uma discussão sobre o processo de implementação de política públicas, cujos elementos mais significativos apontam para a relevância do papel da burocracia no desenho das políticas e o modo como seu poder discricionário altera as trajetórias devido aos fatores organizacionais e de interação entre os atores envolvidos. Os achados da pesquisa apontam para a compreensão sobre as políticas pouco institucionalizadas e fluidas têm custos e gaps de implementação elevados, possibilitando ampla liberdade às interferências da burocracia de ponta, o que pode defini-la como bem sucedidas, quando o seu desenho estiver bem articulado. Para o caso específico da política de saúde da população negra, a composição de uma rede de pontos focais foi uma das saídas bem sucedidas para que uma política conflituosa garantisse a sua existência.
\end{abstract}

Palavras-chave: Implementação. Racismo institucional. Políticas públicas. Burocracia. Discricionariedade.

Mestrado pela Universidade Federal da Bahia (UFBA). Professora Assistente da Universidade Federal do Recôncavo da Bahia (UFRB), do Centro de Ciências da Saúde. Pesquisadora do Grupo de Pesquisa Instituições Políticas Subnacionais (UFBA) e Labtrans (Laboratório humano de estudos, pesquisa e extensão transdisciplinares em integralidade do cuidado em saúde e nutrição, gêneros e sexualidade, da UFRB). 


\begin{abstract}
This paper analyzes how the implementation process of the Healthcare Policy for the Black Population occurred in the city of Salvador, Bahia, between 2005 and 2012. In order to do so, institutional racism, the role of street-level bureaucracy and its discretionary power, and the resources that were used during the policy's implementation were considered analytical categories. So that this process could be accomplished, a Network of focal points was formed with street-level bureaucrats who work in healthcare institutions, with the goal of executing the parameters formulated for the policy in question. Two known approaches were used in order to treat the results: a discussion on the process of public policy implementation, whose more significant elements point to the relevance of the bureaucracy's role in the policies' design and the way its discretionary power alters trajectories due to organizational factors and the interaction with the actors involved. The findings of the research point to an understanding that policies that have low institutionalization and are fluid have high costs and implementation gaps, enabling more freedom for interference from street- level bureaucrats, which may define them as successful, when their design is well articulated. For the specific case of healthcare policy for the black population, the creation of a network of focal points was a successful solution so that a contentious policy could ensure its existence.
\end{abstract}

Keywords: Implementation. Institutional racism. Public policy. Bureaucracy. Discretionary power.

\title{
SOBRE AS CIRCUNSTÂNCIAS DO PROBLEMA: NOTAS INICIAIS
}

O federalismo brasileiro conjuga atribuições dos três níveis de governo, federal, estadual e municipal, cujas competências de cada instância estão inscritas na carta constitucional, algumas delas de ordem exclusiva da união e outras compartilhadas pelos três níveis de governo. Esse arranjo objetiva garantir a distribuição de tarefas e poderes entre as unidades subnacionais e, ao mesmo tempo, a unidade político-econômico-territorial do Estado. Do ponto de vista da implementação de políticas sociais, objeto deste trabalho, análises têm destacado o papel dos governos municipais, apontados como atores importantes na coordenação e facilitação dessas políticas em busca de equidade e eficiência, ampliada pelo fato desta ser a esfera de governo mais próxima da população. Decorrente do processo de descentralização, a partir da premissa de que a centralização decisória do regime autoritário havia gerado ineficiência, corrupção e ausência de participação (ARRETCHE, 2002), tal condição dos estados e municípios indica também dificuldades que precisam ser enfrentadas, devido a diversos fatores como a falta de capacidade de gestão e as desigualdades financeiras presentes na distribuição de recursos das unidades subnacionais, bem como baixo incentivo à cooperação entre as regiões. Aliado a isso, a luta pelo reconhecimento da existência de desigualdades para o acesso às políticas públicas tem sido permeado por diversas reivindicações orientadas a partir das 
identidades mais discriminadas, com destaque às políticas consideradas fundamentais e direitos essenciais, como educação, moradia, saúde.

Esse conjunto de reivindicações evidenciou ao longo desses anos de estabilidade democrática que, somente a garantia de políticas que se pretendem universais não possibilita a todos os grupos sociais benefícios e gozo de condições saudáveis de forma igualitária. Fatores produzidos em outras dimensões sociais são reproduzidos em espaços e instituições que se pretendem neutras. Entre os fatores produzidos nas relações sociais está o racismo presentes também nas instituições, impossibilitando um acesso saudável, universal, não discriminatório às políticas públicas. Para compreender as desigualdades produzidas pelo racismo, uma análise sobre a dinâmica de formação das instituições públicas no país precisa ser revisitada, visto que a universalidade pretendida pelos parâmetros da Constituição de 1988 não eliminou as distorções e práticas discriminatórias históricas e estruturais das instituições, resultantes de relações patrimonialistas e excludentes que orientaram e ainda orientam as regras institucionais. O passado colonialista e escravista brasileiro produziu diferenças acumuladas historicamente que se reproduzem mesmo diante do princípio da universalidade presente na democracia brasileira. A política de saúde não escapa dessa herança e o seu princípio universalista não foi suficiente para superar as iniquidades ocasionadas na vida da população negra produzidas pela dificuldade ou acesso insuficiente à saúde pública no Brasil, adicionada às diversas discriminações e estereótipos ao qual esta população está submetida.

Buscando enfrentar tais desigualdades, os governos brasileiros têm produzido desde a década de 1990, um conjunto de políticas classificadas como reparatórias, dentre as quaisa Política Nacional de Saúde Integral para a População Negra (PNSIPN) que visa garantir direitos no acesso à saúde de forma integral com equidade para esta população. Entretanto, essa e outras políticas racializadas, encontram diversos vetores e pontos de fuga na esfera política, institucional e burocrática. Não há uma convergência de discursos na classe política acerca da existência do racismo de modo estruturante nas relações sociais, tampouco a sua presença nas regras das instituições do país. Aliado a isso, o poder sobre as agendas governamentais e políticas prioritárias é distribuído entre união, estados e municípios, o que muitas vezes se apresenta como mais uma barreira para que estas legislações avancem, visto que é necessário convencer os governos nas três esferas. Neste aspecto, as análises têm indicado condições diferenciadas nas unidades subnacionais nas quais há uma maior participação social dos movimentos negros mobilizando agendas governamentais com tais pautas de modo mais freqüente, sendo esse o espelho de Salvador, município 
que despontou nacionalmente ao inserir na agenda governamental esta política no ano de 2005, aproveitando a janela de oportunidades das eleições municipais daquele ano, com amplo apoio e pressão dos movimentos negros.

Este artigo buscou levantar quais fatores convergiram para que a política de saúde para a população negra fosse implementada em Salvador durante o período compreendido entre 2005 e 2012, considerando o contexto político, suas mudanças e atores envolvidos nesta tarefa. O recorte temporal deste trabalho baseou-se em dois governos gestados com mudanças de ordens partidárias e novas coalizões que promoveram também alteração no curso da política. Estudos já foram realizados para levantar e compreender como a política de saúde para a população negra foi agendada e formulada neste município, considerando os atores governamentais, a burocracia e a participação das organizações dos movimentos negros que estiveram presentes nesta etapa. Araújo e Teixeira (2013), no período compreendido entre 2005 e 2006 realizaram um extenso levantamento, cujos resultados apontaram as características dos atores e sua vinculação a organizações dos movimentos negros, concluindo que o contexto político e institucional no período foi fundamental para a inclusão do tema em questão na agenda do governo recém eleito. Tendo tal condição como pano de fundo, pretende-se, neste trabalho, explicar como se deu o processo de implementação da política de saúde da população negra no município de Salvador, durante os anos de 2005 a 2012. Para isso, consideramos alguns fatores importantes: a existência do racismo institucional, visto que no desenho da política de saúde para a população negra o racismo institucional é apresentado como uma categoria analítica a ser enfrentada para que a política tenha êxito em seu ciclo; a relevância da burocracia de rua no processo, a partir da formação de uma rede de pontos focais nos distritos e unidades de saúde do municípioº ${ }^{2}$; as ações desenvolvidas pelo núcleo institucional para o desenvolvimento da política alocado dentro da Secretaria Municipal de Saúde Grupo de Trabalho de Saúde da População Negra (GTSPN)/ Assessoria de Promoção da Equidade Racial em Saúde (ASPERS).

\section{A “BRASILIDADE” DO CONCEITO RACISMO INSTITUCIONAL}

O conceito de racismo institucional é bastante apropriado para ampliar compreensão sobre as desigualdades a partir do espectro racial, visto que a construção social e histórica presentes foi herança das relações escravocratas que fundaram o Estado brasileiro, sem que em algum momento da trajetória

Rede formada por funcionários dos distritos e unidades com o objetivo de implementar a política de saúde da população negra em seus respectivos territórios de trabalho. 
institucional, a questão do racismo como elemento estruturante tivesse sido considerada presente nas práticas e na ordem institucional. Compreender tais arranjos também auxiliará a desvelar as desigualdades para a promoção de políticas públicas, pois:

O racismo institucional é o fracasso das instituições e organizações em prover um serviço profissional e adequado às pessoas em virtude de sua cor, cultura, origem racial ou étnica. Ele se manifesta em normas, práticas e comportamentos discriminatórios adotados no cotidiano do trabalho, os quais são resultantes do preconceito racial, uma atitude que combina estereótipos racistas, falta de atenção e ignorância. Em qualquer caso, o racismo institucional sempre coloca pessoas de grupos raciais ou étnicos discriminados em situação de desvantagem no acesso a benefícios gerados pelo Estado e por demais instituições e organizações. (CRI, 2006, p. 22)

$O$ racismo institucional não se expressa somente a partir de atitude explícita ou declarada. Há uma indeterminação do sujeito da ação. Ele é difuso e estrutural, se apresentando muitas vezes pela ausência ou precariedade do serviço prestado pelo Estado ou pelo não acesso a uma política pública. Pode também se apresentar revestido pelo véu da desculpa da incompetência ou inabilidade para a democratização do acesso a oportunidades. O racismo institucional está para além das relações pessoais e interpessoais, não precisando do algoz para ser exercitado. Ele não pode ser punido, pois não há enquadramento na constituição, visto que o autor é o próprio Estado.

Este conceito foi cunhado na década de 1960, no bojo da luta pelos direitos civis dos negros nos Estados Unidos, sendo apresentado no livro Black Power: The politics of liberation (1992) por dois ativistas do movimento Panteras Negras. Dentre os objetivos da criação do conceito eram de especificar como se manifesta o racismo nas estruturas da organização da sociedade e nas instituições, descrever os interesses, ações e mecanismos de exclusão estabelecidos pelos grupos racialmente dominantes. Assim, seria possível fazer denúncia das estruturas do poder branco que alijava e oprimia a população negra, no mesmo passo em que desejava propor as condições para que as estruturas do poder negro também pudessem fazer parte do Estado norte-americano. Segundo os autores, o racismo tem como predicação forjar decisões e políticas que mantenham em subordinação um grupo racial em detrimento do outro. Em sua forma institucional, ele é mais difícil de identificar e recebe menos condenação públi$\mathrm{ca}$, se reproduzindo a partir de políticas institucionalmente racistas, inclusive através de pessoas negras que são cooptadas pelo sistema. (LOPEZ, 2012)

$\mathrm{Na}$ Inglaterra, durante os anos de 1980, esse conceito foi introduzido como instrumento de proposição de políticas públicas em busca do empoderamento 
da população negra e como argumento para a denúncia da ineficiência do Estado em relação a determinados grupos raciais, principalmente do poder judiciário com a população negra. Este evento foi mobilizado a partir da morte de um jovem negro, Stephen Lawrence por cinco homens brancos e o procedimento institucional do judiciário inglês conduziu a absorção dos culpados, negligenciando várias etapas da investigação. A averiguação foi classificada como tendenciosa e o próprio governo assumiu que os inquéritos policiais eram racistas (LOPEZ, 2012)

Neste trabalho será adotada a perspectiva com influência inglesa, visto que foi este que norteou as ações do movimento negro frente ao governo brasileiro após a Conferência Mundial contra o Racismo, Xenofobia e discriminações correlatadas, realizada em 2001 e o que estruturou o Programa de Combate ao Racismo Institucional (PCRI), implementado a partir de 2005, numa parceria entre: Secretaria de Políticas de Promoção da Igualdade (SEPPIR), o Ministério Público Federal (MPF), Ministério da Saúde (MS), Organização Pan-Americana de Saúde (OPAS), Departamento Britânico para o Desenvolvimento Internacional e Redução da Pobreza (DFID), Programa das Nações Unidas para o Desenvolvimento (PNUD).

Uma aproximação do conceito de racismo institucional com a discussão de Edson Nunes (2010) sobre os quatro padrões para as relações entre a sociedade e as instituições formais no Brasil é uma importante ferramenta para que haja compreensão sobre a forma como as instituições públicas e privadas privilegiam determinados grupos e redes a partir de regras anteriormente institucionalizadas e como se mantém presentes e atuantes mesmo com a inauguração de um conjunto de ações que visam promover a superação das desigualdades e do racismo. Tal compreensão sobre o racismo institucional brasileiro coabitando com políticas públicas antirracismo é mais um dos marcadores de um sistema político que promove a convivência entre elementos da tradição e da modernidade, estabelecendo regras que não se excluem, mas interagem. São demonstrações dos interesses diversos presentes na arena política e como os governos têm adotado medidas para a resolução dos conflitos apresentados pelos diversos grupos de interesses, garantindo a governabilidade e como vem, ao longo dos tempos, incorporando novos atores sociais e suas demandas ao sistema político.

Dessa forma, o racismo institucional se alimenta pela prática burocrática das instituições a partir da crença na inferioridade de determinados grupos étnicos e raciais, bem como a estrutura institucional montada para um Estado que se pretende universalista, mas foi forjado sobre relações escravistas e não adotou em sua trajetória institucional medidas que buscasse reordenar essas 
desigualdades. É pelo entendimento sobre o papel do Estado como definidor das normas institucionais e implementador de políticas públicas, também devido ao processo de mudança de rota institucional e incorporação de padrões para a relação entre Estado e sociedade que a discussão sobre racismo institucional está voltada para a estrutura do Estado, com o objetivo de compreender como o racismo se realiza com o sistema estrutural e opera de forma a induzir, manter e condicionar a organização e a ação estatal, suas instituições e políticas públicas produzindo e reproduzindo a hierarquia racial, ou seja, privilegiando um grupo racial em detrimento do outro. Sua manifestação se dá pelas condições materiais, ocasionando acesso diferenciado em relação à qualidade na educação, saúde, segurança pública, habitação, trabalho, dentre outras políticas. Também pode ser mensurado através do acesso às instâncias de poder no que tange a informação, recursos econômicos, representação política e controle da mídia. Tais desigualdades são acúmulos, produto da formação histórica que designou vantagem para uns e desvantagens para muitos, mas a persistência dessas diferenças até a contemporaneidade é produto da estrutura institucional que possibilita a perpetuação do racismo, mesmo com a promoção de ações que desejam criar as condições de reduzir as discrepâncias raciais.

Sobre a produção e reprodução do racismo a partir das instituições, Camara Jones (2000) desenvolveu um quadro que auxilia na compreensão de tipologias características do fenômeno a partir da ordem psicológica até a sua manifestação nas estruturas institucionais. Apesar do modelo subsidiado na experiência norte-americana, aonde as relações raciais se desenvolveram a partir de outras estratégias, a conformação sócio racial é linear, sendo possível notar a presença das esferas de manifestação do racismo como um tipo ideal que serve de parâmetro para aproximações de acordo com as interações territoriais. No quadro formulado por Jones (2000) é possível verificar três níveis ou manifestações do racismo: pessoal, interpessoal e institucional. O nível pessoal diz respeito à internalização das mensagens sobre racismo, se apresentando na ordem da descrença em si mesmo, na ideia de inferioridade (pessoas negras) ou superioridade (pessoas brancas). Ele se apresenta como atitudes manifestadas por indivíduos que causam morte, ferimentos, destruição de propriedade ou de negação de serviços ou oportunidade. O racismo interpessoal se apresenta sob a forma da discriminação ou preconceitos manifestados, ou seja, os pressupostos sociais sobre as habilidades, motivos e intenções das pessoas devido a sua cor. Muitas vezes esse tipo se apresenta em parceria com o pessoal e o institucional.Está presente na ação das instituições, sendo muitas vezes exercitado pela burocracia de rua. O último nível, racismo institucional, é definido como o 
acesso diferenciado aos bens, serviços e oportunidades da sociedade por causa da raça. Ele está presente nas normas, às vezes legalizadas ou como uma desvantagem herdada. É estrutural, pois há códigos nas instituições manifestados através do costume, prática e da lei, de modo que não é necessário identificar um autor. O racismo se apresenta no bojo das instituições como omissão do e no serviço na face à necessidade. A visibilidade para o sujeito indeterminado presente nos procedimentos burocráticos das instituições é uma contribuição importante desse quadro analítico, visto que possibilita verificar o racismo dissociado dos atos, intenções ou mesmo consciência dos autores promotores. Esse sujeito causador do racismo institucional é resumido por Wieviorka (2007) ao apresentar um dilema muito comum nas instituições brasileiras na atualidade, quando estas são administradas ou governadas por pessoas não racistas ou não crentes em teorias racistas e ainda assim diagnostica-se a presença de práticas excludentes pelo espectro raça/cor. O que ocorre é que esses dirigentes podem estar sujeitos ao racismo inconsciente e subjugados às normas institucionais racializadas que preterem a população negra. Nesse atalho, é possível cada vez verificar a admissão da existência do racismo, entretanto prová-la é requer a iluminação de algumas esferas sociais. A prova mais relevante da sua existência está na condição de inferioridade da população negra, que pode ser evidenciada por qualquer indicador social que se escolha; seja nos números sobre mortes violentas, sistema prisional, baixo acesso ao serviço de saúde, desempregos e subempregos, baixa escolaridade, dentre outros.

Vale ressaltar que, apesar desta abordagem indicar para uma (des)responsabilização dos segmentos dominantes da sociedade em relação às desigualdades raciais, devido ao fato de, aparentemente, não serem conscientes do racismo, ainda assim, esses segmentos são beneficiados por essas desigualdades, usufruindo do status quo da branquitude e todas as oportunidades e privilégios presentes numa sociedade racializada. Dessa forma, numa sociedade em disputa, como é a sociedade capitalista, as pessoas sabem como o racismo produz capitais sociais, delegando privilégios e alijamentos, uma vez que se beneficiam das oportunidades concedidas a determinados grupos raciais. Adiciona-se ainda, o fato da estrutura escravagista de fundação dos Estados modernos americanos, quando em sua formação, a relação de exploração e desigualdade esteve assentada em relações de trabalhos desumanas e a construção de uma consciência coletiva de menos humanidade para a população negra.

Retornar à discussão sobre poder neste ponto é fundamental visto que, por definição, o racismo institucional se apresenta enquanto abstração, resultante da organização da estrutura do Estado brasileiro. Para que não haja 
afastamento do conceito e dos fenômenos com os quais ele se relaciona é importante fazer uma correlação com outros conceitos que nos auxiliam a materializar uma próxis, ${ }^{3}$ neste caso, o racismo institucional, conforme está sendo abordado. A construção de uma materialidade empírica para analisar é uma aproximação, visto que o conceito em questão está subsidiado no campo das simbologias evidenciando como estas repercutem sobre as relações de poder. Pierre Bourdieu (2002) apontou para as desigualdades produzidas numa sociedade hierarquizada, cujas condições materiais e simbólicas importam para a apropriação de poder e privilégios, fomentando uma distribuição desigual dos recursos aos seus membros a partir desses marcadores. Trata-se de capitais de ordem material ou simbólica: capital econômico, se referindo à renda, salários, imóveis; capital cultural, como saberes e conhecimentos reconhecidos por diplomas e títulos; o capital social, que diz respeito às relações sociais que podem ser revertidas em capital, relações que podem ser capitalizadas; e por fim o capital simbólico, resumindo-se ao prestígio e/ou honra. Interessa-nos esta conceituação, pois a discussão sobre o racismo institucional orienta-se a partir da simbologia, repercutindo na dimensão material, devido ao fato do racismo institucional se apresentar na dimensão simbólica. É importante notar que a associação entre o nível socioeconômico persiste até os dias atuais por causa dos fatores estruturais que perpetuam essas injustiças históricas. Em outras palavras, é por causa do racismo institucional que há uma associação entre condição socioeconômica e raça no país.

A política analisada nesse estudo é resultado do desdobramento desse conjunto de simbologias no campo material. Se, num Estado democrático que pretende universalizar todas as ações de saúde voltadas para a sociedade, ainda assim diagnosticaram-se discrepâncias em relação ao acesso e utilização desses serviços e nelas há conclusão de que essa variação é condicionada por causa da cor/raça e etnia, percebe-se que a argumentação tecida até aqui encontra no campo empírico validação.

Utilizo a terminologia proxy neste trabalho ao invés de indicador, pois alguns dados que serão abordados neste trabalho não existe desagregação oficial a partir do espectro cor, assim, serão utilizadas aproximações. As informações socioeconômicas do censo do IBGE têm bancos de dados robustos considerando raça, gênero e geração, entretanto esses dados são mais consistentes no que tange a esfera federal e esse trabalho se orienta para as unidades subnacionais, no caso, município de Salvador. 


\section{PRÁTICA E ESTILO DOS PONTOS FOCAIS: A DISCRICIONARIEDADE PODE PROMOVER A IMPLEMENTAÇÃO DE POLÍTICAS COM BAIXO ENRAIZAMENTO}

O processo de implementação das políticas públicas perpassa pela atuação dos burocratas do nível de rua, atores chaves que influenciam o percurso que tais políticas irão seguir. Isso é resultado de uma combinação de fatores, entre eles a limitação de recursos, falta de clareza nos desenhos das políticas, aliado aos interesses próprios dos burocratas como categoria ou individualmente. Esses estilos, potencialidades, conjunto de valores e preferências, promove o exercício da discricionariedade que por muito tempo foi rejeitado pelos teóricos, sendo analisado como uma distorção do papel do burocrata, uma ação que deveria ser corrigida para que as políticas fossem eficientemente implementadas. (LIPSKY, 2010) No entanto, essa posição tem sido reavaliada a partir da compreensão de que a discricionariedade pode ser necessária, principalmente para as políticas implementadas sob circunstâncias desfavoráveis ou atípicas, mesmo reconhecendo o insulamento e poder delegado aos burocratas no exercício de tal discricionariedade. Ainda assim, considerar as preferências, estilos e conhecimento profissional dos burocratas como categorias que advogam a favor do sucesso de implementação de políticas públicas que nasceram condenadas ao fracasso pode ser essencial na compreensão dos variados estudos nesse campo. (LOTTA, 2010).

Este é o caso da política de saúde para a população negra ao ser implementada em Salvador, durante os anos de 2005 a 2012. Contando com um conjunto de ações concentradas nos três primeiros anos no município, após muitas dificuldades de ordem institucional, política, recursos; sua sobrevida pôde ser mapeada nos anos seguintes a partir das ações da burocracia de rua, atuantes nos distritos sanitários e unidades de saúde, considerando fatores relacionais aliado aos estilos de cada burocrata responsável pela implementação. A pesquisa realizada para a dissertação de mestrado (QUEIROZ, 2015) demonstraram como a discricionariedade foi importante para que a PNSIPN tivesse continuidade frente às dificuldades, tendo como principal agente implementador a ação dos pontos focais dos distritos e unidades de saúde e o seu principal recurso investido as competências individuais e o compromisso com o sucesso da política desses burocratas do nível de rua. Aliado a isso, a tarefa delegada aos pontos focais (responsabilidade para disseminar as ações do GTSPN/ ASPERS em seus distritos sanitários) e a compreensão sobre suas responsabilidades enquanto pontos focais (implementar a política dentro dos seus distritos e unidades, a 
partir da formação de seus pares e realizar atividades referente à política em seus territórios, bem como informar à população atendida sobre a existência da política e seus direitos em ter um atendimento livre de discriminação racial) possibilitaram o exercício da discricionariedade com bastante elasticidade.

Numa abordagem em que analisa como se deu o processo de implementação do Programa de Saúde da Família (PSF) em três diferentes municípios de São Paulo, Lotta (2010) constatou em sua tese de doutorado que este processo é um complexo que envolve pessoas, vontades, necessidades, poder, recursos, disputas, conhecimentos e desconhecimentos o que condiciona processos diferentes para a implementação da mesma política. Ela considerou que dois grandes grupos de fatores alteram a forma como a implementação acontece: organizacionais, ligados à gestão das unidades básicas e ao funcionamento das equipes de saúde da família e os fatores relacionais, vinculados às redes sociais dos agentes e às afiliações e trajetórias.

Este trabalho utilizou os mesmos dois grupos de fatores para a pesquisa em questão: fatores organizacionais e fatores relacionais. Os fatores organizacionais se apresentam sob a perspectiva das condições possíveis para o desenvolvimento das atividades que garantem o curso da implementação das políticas nos distritos e/ou unidades; para os fatores relacionais, consideramos os estilos dos burocratas implementadores, promovendo o grau de facilidade ou dificuldade dentro de seus respectivos distritos e/ou unidades. Apesar das categorias criadas por Lotta nortearem as que foram formuladas para esta pesquisa, elas não são idênticas. Isso se deve ao fato dos fatores organizacionais aqui categorizados referirem-se aos postos ocupados pelos pontos focais, pois esta condição influenciou no desempenho de suas ações para esta pesquisa. Os fatores relacionais estão vinculados às relações desenvolvidas com os seus pares, superiores ou subalternos no ambiente de trabalho. As demais condições foram as mesmas, pois foram desenvolvidas pela mesma área institucional, até a política alcançar os distritos. Isso se difere do campo de análise da pesquisadora citada que utilizou três cidades diferentes. Dessa forma, faz-se necessário apresentar as categorias formuladas para a presente pesquisa:

a. Atividades: o que foi realizado no distrito com vistas à implementação da política;

b. Dificuldades: o que foi identificado como elemento presente que dificultou a realização do que foi realizado ou foi planejado e não realizado;

c. Facilidades: o que facilitou a realização das atividades;

d. Mobilização: resposta dos demais profissionais para participar das atividades e realizar as propostas para a implementação da política; 
e. Orientação: compreensão sobre qual o papel do ponto focal;

f. ASPERS - DS: relação e apoio da ASPERS com o distrito;

g. Racismo institucional: barreiras institucionais relacionadas à questão da raça/cor.

As categorias enumeradas acima foram organizadas de acordo com roteiro de entrevista formulado e aplicado aos informantes. A única categoria que não se apresentou explicitada no roteiro de perguntas aplicadas nas entrevistas foi racismo institucional, entretanto ela foi destacada por todos os informantes durante os seus relatos, na ocasião da pergunta sobre as dificuldades.

Buscando uma análise mais qualificada para compreender como as categorias se relacionam optamos por utilizar uma representação gráfica extraída da metodologia de redes organizada com o software ATLAS TI. Assim, a relação estabelecida entre os fatores que promoveram diferentes desenvolvimentos da política nos distritos e unidades de saúde, pôde ser apresentado de acordo com as relações estabelecidas a partir dos vetores ofertados pelo sistema. Esse cruzamento de informações através do software possibilitou uma análise mais clara dos condicionantes da política em questão. Os vetores utilizados foram os seguintes:

a. Causa: aconteceu e estava planejado e está explícito na fala dos informantes;

a. Parte: aconteceu, mas não estava previsto e está explícito na fala dos informantes;

a. Contrário: não deveria ter acontecido e está explícito na fala dos informantes;

a. Associado: associação da pesquisadora, não está explícito na fala dos informantes.

Os vetores estão organizados para este trabalho a partir da dinâmica acima descrita. É importante ressaltar que, o apoio da ferramenta auxilia ao pesquisador na definição sobre como as categorias se relacionam em sua pesquisa. Esses vetores utilizados podem assumir outros comportamentos ou significados, entretanto, diante do conjunto universo dessa pesquisa para que os resultados apontados sejam alcançados, as categorias e os vetores devem assumir estritamente o significado acima exposto.

A partir das informações concedidas pelos informantes, o próprio sistema orientou as relações entre as categorias de acordo com os vetores e a principal observação que pode ser feita no resultado apresentado pelo software é a centralidade da categoria racismo institucional para todas as possibilidades de ordenamento montado pela ferramenta. As três possibilidades: duas vezes 
a categoria centralizada é o racismo institucional e a outra foi nenhuma categoria selecionada para a centralidade. Abaixo segue as possibilidades montadas pelo ATLAS TI.

Figura 1 - Modelo 1 de Relações formadas com as categorias analisadas.

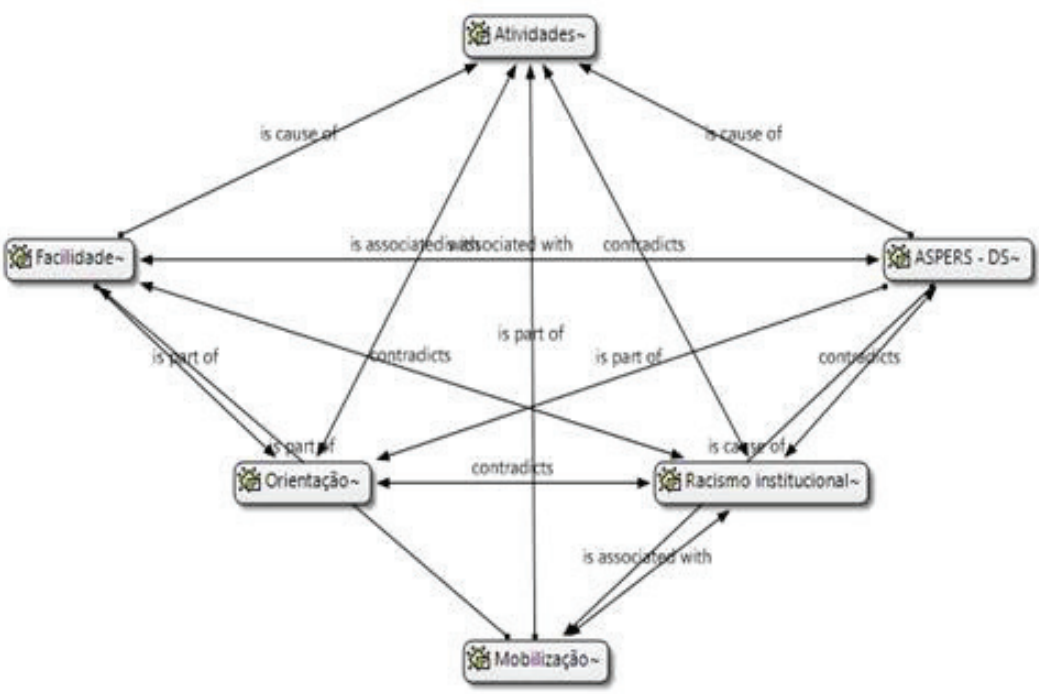

Fonte: elaborada pela autora.

Figura 2 - Modelo 2 de Relações formadas com as categorias analisadas.

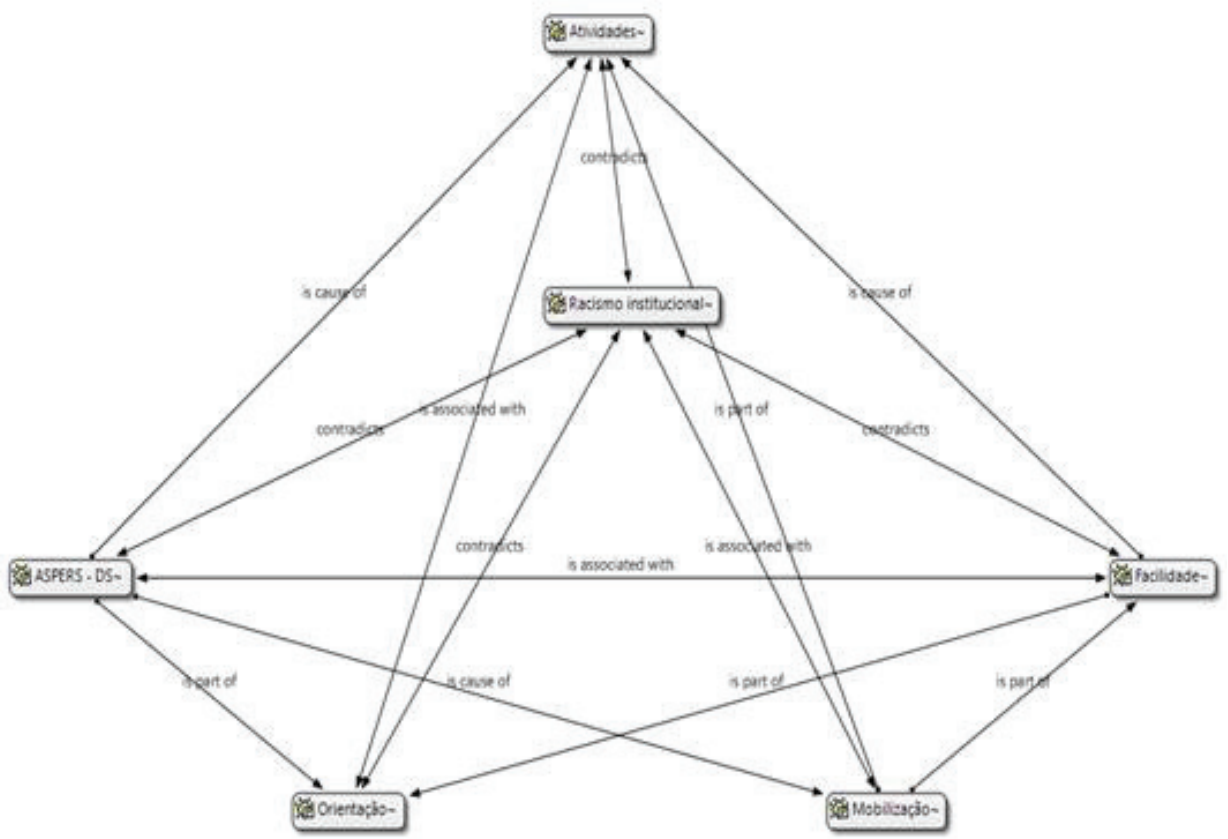

Fonte: elaborada pela autora. 
Figura 3 - Modelo 3 de Relações formadas com as categorias analisadas

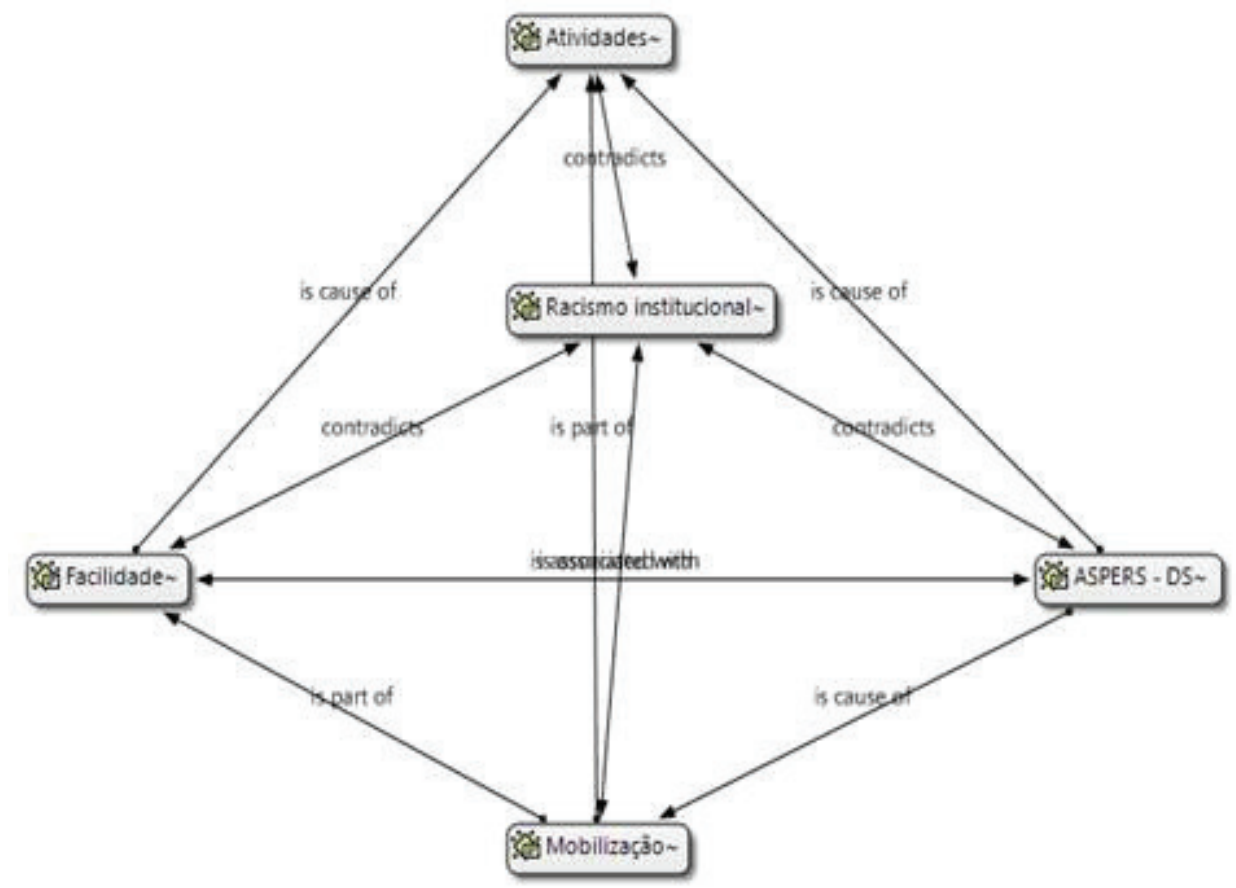

Fonte: elaborada pela autora.

As três relações acima foram organizadas livremente pelo software, havendo inicialmente a inserção das categorias e a vetorização das mesmas de acordo com a descrição do que cada vetor significa. Cada categoria pôde se relacionar mais de uma vez com as outras, sendo vinculada com vetores diferentes. A organização geométrica, ou seja, a distribuição espacial das categorias coube à ferramenta tecnológica. O que podemos notar com o auxílio do Atlas TI foi a centralidade da categoria racismo institucional, pois a distribuição espacial a centralizou em todas as tentativas de reordenação das categorias oferecidas pelo software.

O fato de o racismo institucional ser alocado pela ferramenta em todas as versões da montagem da rede como central ao ser iniciada com a ASPERS-DS possibilita reflexões importantes acerca da pesquisa desenvolvida; uma delas é sobre os constrangimentos enfrentados pela política formulada para reduzir as iniqüidades raciais em saúde, que a princípio, teria grandes chances de sucesso em sua implementação, devido a um conjunto de fatores, entre eles, a presença de atores na burocracia interessados ou engajados para o seu sucesso, encontra barreiras típicas do racismo institucional que interrompe ou fraciona o cumprimento de seu ciclo. Podemos apontar questões interessantes observadas no campo sobre o desenvolvimento da política, seus territórios mais 
bem sucedidos e os que mais apresentaram dificuldades em implementar, bem como a capacidade para mobilização.

Foi possível notar que os estilos dos pontos focais foram grandes motores para o sucesso da implementação em seu distrito. Os quatro distritos mais bem sucedidos (Itapagipe, Brotas, Barra/ Rio Vermelho, Cajazeiras) os informantes apontaram o bom relacionamento com a equipe de suas áreas de atuação, não demonstrando problema para que os pares fossem às atividades ou reuniões quando convocados. Importante notar que estes distritos melhores sucedidos na implementação da política tinham como ponto focal pessoas que estavam na gestão e formação de nível superior: mulher branca, enfermeira, bióloga sanitarista e os dois últimos assistentes sociais (Barra/ Rio Vermelho, uma mulher branca é o ponto focal, enquanto que Cajazeiras estava sob a responsabilidade de um homem negro). Os dois distritos médio-sucedidos (São Caetano/ Valéria e Subúrbio) os informantes apresentaram relatos de dificuldades na formação da rede, diferenciaram períodos com mais propício e outros mais difíceis; identificaram como empecilhos o racismo e dificuldade de comunicação (os dois distritos foram capitaneados por mulheres negras). Os pontos focais distritais também tinham nível superior (a primeira formada em direito, a segunda assistente social), mas nenhum dos dois PF tinha função na gestão. Além disso, a ponto focal do DS São Caetano Valéria exercia a função de agente comunitário de saúde. Para elas a grande dificuldade estava em serem atendidas quando convocavam os demais profissionais para atividade/reunião/conversa. Coincidentemente, nesses dois casos os pontos focais são pessoas negras e relataram experiências de racismo sofridas durante o seu exercício profissional durante a entrevista. Os outros quatro pontos focais distritais que eram agentes comunitários de saúde (Boca do Rio, Cabula/Beiru, Pau da Lima e Liberdade) apontaram muitos problemas e conflitos com a tarefa de mobilizador. Identificaram com nitidez na fala o racismo aliado à função de agentes comunitários de saúde e também eram pessoas negras. Participavam com maior freqüência do chamado da ASPERS e não foi possível registrar nenhuma atividade iniciada no distrito por convocação dessas representações.

Interessantes encontros nos relatos dos informantes sobre o racismo: todos os pontos focais negros relataram experiências com o racismo que dificultaram na implementação de ações para a política de saúde da população negra. Aos que estavam em alguma função de gestão, conseguiam realizar o que propunham enquanto ponto focal, mas apontavam o descontentamento da equipe e a identificação com a cor, esquecendo que é uma orientação legal a implementação da política. Aos que estavam numa função subalternizada dentro de seus 
distritos, aliado ao fato de ser negro, não conseguiram avançar em atividades dentro dos distritos, além de demonstrarem um grande desgaste ao tentar realizar tal tarefa. Outro ponto convergente é o fato de todos os informantes terem relatado que os distritos que enfrentaram dificuldade em implementar a política tinham como ponto focal distrital um Agente Comunitário de Saúde (ACS).

Destaca-se também que todos os distritos reconheceram o trabalho desenvolvido em Itapagipe, sendo este indicado várias vezes como exemplo de melhor sucedida pelos entrevistados com a utilização da técnica snow ball, entretanto, a referência distrital foi descrita em diversos momentos como menos mobilizada do que os pontos focais das unidades. Este ponto nos interessa porque apresenta uma contradição curiosa frente aos relatos dos entrevistados, que em geral apontaram ser fundamental a capacidade do ponto focal distrital em mobilizar e envolver os demais de seu território para o sucesso da política. No caso desse distrito, apontado diversas vezes como referência e confirmado através do levantamento das ações realizadas, o peso do ponto focal distrital não foi idêntico ao apresentado nos relatos do que seria o modelo para ser bem sucedido. Há de se relatar que nesse distrito, as referências entrevistadas das unidades são todas mulheres brancas ${ }^{4}$, inclusive a referência distrital. Podemos resgatar a discussão realizada anteriormente sobre a relação entre o racismo institucional e o racismo nas instituições, ao interseccionalizar as dificuldades institucionais enfrentadas para a implementação da política, resultado do modelo pelo qual as instituições brasileiras foram forjadas, à presença dos valores individuais na prática laboral dos burocratas.

Outra questão interessante diz respeito ao estilo dos burocratas de rua e pontos focais desta política; há um engajamento com o sucesso e importância dessa política, aliado ao processo de descoberta do racismo. Assim, a defesa e o interesse no processo de implementação dessa política, articula o seu posto de trabalho com o engajamento social, ao mesmo tempo em que constrói uma identidade militante que muitas vezes sobrepõe à identidade burocrata. Isso pode ser notado nos relatos em que os demais burocratas associavam qualquer atividade vinculada à questão racial e negra às referências territoriais. Assim, qualquer seminário que fosse para discutir temáticas raciais mesmo que estivesse distante da área saúde da população negra, a escala estaria direcionada a este profissional. Esta vinculação foi apontada nos relatos como uma das dificuldades para a continuidade da política e como resposta aos demais colegas

Essa classificação não se baseou na autodeclaração. Há também, uma referência bastante ativa numa das unidades, entretanto, ela foi transferida do Distrito Barra/Rio Vermelho, começando a implementação nesse DS. 
com dificuldade de compreender, os pontos focais marcavam que a contribuição para a implementação da política em questão é parte de suas atividades profissionais, orientada por lei contida no Estatuto da Igualdade Racial (nacionalmente) e aqui através da publicação do Plano Municipal de Saúde (2006 -2009).

\section{CONSIDERAÇÕES FINAIS}

A realização deste trabalho buscou respostas para as seguintes questões: como se deu o enfrentamento do racismo institucional consoante às estratégias de implementação da política de saúde da população negra em Salvador entre 2005 e 2012 e quais as diretrizes marcaram a atuação da burocracia de rua e dos órgãos governamentais no processo de implementação, observados os objetivos formulados para a política em questão. Para isso, dialogou-se com duas abordagens referenciadas para dar conta dos achados resultantes da pesquisa: uma discussão sobre o processo de implementação de política públicas, cujos elementos mais significativos apontam para a relevância do papel da burocracia no desenho das políticas e o modo como seu poder discricionário altera as trajetórias devido aos fatores organizacionais e de interação entre os atores envolvidos. (LOTTA, 2010) A outra discussão que subsidiou as análises recupera os principais argumentos sobre o racismo institucional, ao conceituá-lo como inerente às instituições atuais devido aos processos de modernização que não rejeitou as normas tradicionalistas definidas durante o período de negação de direitos à população negra. Assim, normas de práticas típicas de instituições racistas convivem com as normas que buscam a inclusão da população negra. Também se diferenciou a prática do racismo nas instituições e racismo institucional, sendo o primeiro a prática dos burocratas a partir de suas escolhas, preferências e concepções, enquanto, que o segundo diz respeito às normas, regras que não dependem de escolhas de nenhum representante. (JONES, 2000) Isto porque, a política de saúde analisada tinha como um dos seus objetivos o enfrentamento ao racismo institucional, visto que este é notado como o principal empecilho para o acesso a uma saúde de qualidade pela população negra.

Do ponto de vista do debate sobre o desenho e formulação de políticas públicas, evidenciou-se um paradoxo em relação ao desenho de tais políticas, pois enquanto algumas não funcionam porque tem uma orientação e percursos muito fluídos dando vazão às interferências dos burocratas, por outro lado, essa estratégia pode ser bem sucedida no caso de políticas forjadas sob grande conflito e pouca adesão burocrática. Foi possível verificar isso no caso da política de saúde da população negra. 
Enquanto políticas pouco institucionalizadas e fluidas têm custos e gaps de implementação elevados devido à liberdade que promovem, principalmente para as interferências da burocracia de ponta, por outro lado, essa estratégia pode ser bem sucedida no caso de políticas bem articuladas, do ponto de vista de seu desenho. Foi possível verificar isso no caso da política de saúde da população negra, que mesmo com parâmetros muito bem definidos no que tange a sua concepção nacional, descrita sob a forma de lei e também no âmbito municipal, publicada no diário oficial do município, a estratégia de formação da rede de pontos focais com uma tarefa ampla e de baixo controle institucional, aliada a uma convocação para compor este instrumento através de uma identificação individual foram duas saídas bem sucedidas para que uma política conflituosa garantisse a sua existência. A ampla orientação de rota possibilitou que os pontos focais definissem o que seria feito em suas unidades e distritos. Tradicionalmente, há críticas para políticas com baixa definição sobre os percursos para a implementação, entretanto, o fato da política em questão ter sido fluída possibilitou que os pontos focais enfrentassem as adversidades contidas em seus distritos com as suas limitações e mantivessem viva a política dentro dos seus respectivos territórios, mesmo nos momentos em que ela dava sinal de esgotamento no âmbito da gestão.

Retomando as questões de pesquisa, é possível organizar alguns pontos que convergiram a partir das análises cruzadas pelo software e pela análise atenta e cuidadosa da pesquisadora no que diz respeito aos processos de implementação da política. Um achado bastante interessante é a centralidade da categoria racismo institucional, pois mesmo ao traçar uma política que tenha por objetivo reduzir as iniqüidades produzidas pelo racismo e tenha no escopo o enfrentamento a ele, aliado ao comprometimento de uma burocracia engajada, ainda assim, esta categoria não se ausenta. Pelo contrário, o racismo institucional é central e como categoria analítica, articula todas as outras levantadas para esta pesquisa. Isso pôde ser verificado nos relatos dos informantes e reconhecido pelo software. Conectando essa informação e as discussões apresentadas, podemos refletir sobre os debates que têm sido travados sobre a discricionariedade, apresentando outra abordagem para além da mera rejeição às decisões legais, institucionalizadas e validadas pelas instituições e agir de acordo com os seus interesses e valores, dificultando o estabelecimento de regras e condutas que promovam o enraizamento das políticas e programas para além da existência de governos e gestões. Esta mesma discricionariedade pode garantir a realização de ações que não seriam promovidas a partir de diretrizes legais, devido ao seu baixo enraizamento e falta de recursos garantidos para 
a sua implementação, para políticas que tem o perfil semelhante às raciais. Caso a burocracia de rua não tivesse o poder discricionário, muito mais difícil seria a sobrevivência da política de saúde da população negra ao longo desses 8 anos. A existência de uma rede-militante que deu sustentação à política garantiu a perenidade na implementação, à despeito do prestígio e variações no campo da composição partidária que geriu o governo municipal no período analisado. Podemos apontar que a discricionariedade se confundiu com um ativismo político, muitas vezes encontrado nas organizações de movimentos sociais, cujo investimento de recursos é viabilizado pelos membros das organizações, buscando o sucesso do resultado. Isso pôde ser notado na implementação dessa política, quando os investimentos eram captados ou próprios dos pontos focais, avançando em relação ao que se espera de um burocrata a serviço do Estado, neste caso, para a política de saúde da população negra em Salvador.

Os pontos elencados acima propõem questões importantes a partir das conexões estabelecidas, formando um diálogo interessante entre a descentralização, discricionariedade e o racismo institucional nas instituições brasileiras. Caminhos apontados no bojo da redemocratização buscavam incansavelmente empoderar os municípios no compartilhamento de responsabilidades para a execução das políticas, visto que esta é a esfera com maior proximidade com a população. Entretanto, o grau de insulamento dos municípios possibilitou que as decisões governamentais nacionais não sejam necessariamente efetivadas, devido aos amplos poderes dos municípios, que podem definir as suas próprias agendas locais. Isso fortalece as definições da esfera política que precisa ser convencida da importância dos temas no âmbito municipal. Outro ponto interessante é sobre a discricionariedade, que por muito tempo foi vista como vilã para o processo de institucionalização das decisões estatais. No entanto, podemos encontrá-la exercendo outro papel; no caso dessa política foi a discricionariedade que garantiu a continuidade da decisão estatal, se sobrepondo às decisões governamentais. A prática discricionária pode não ser um empecilho para um ótimo desempenho da capacidade do Estado e cumprimento das ações governamentais nem sempre será a solução para que as políticas alcancem grupos historicamente desprivilegiados. Relevante também é compreender que a categoria racismo não é somente um viés, quando o pesquisador compreende a relevância das relações raciais para o entendimento sobre as desigualdades existentes na sociedade brasileira, tampouco uma categoria que deve ser adotada por pesquisadores militantes, pois os estudos têm apontado insistentemente e confirmam que o racismo não é uma faceta presente em alguns fenômenos; pelo contrário, ele é estruturante da sociedade brasileira, nas instituições e até mesmo os valores foram erguidos a partir de tal concepção. 


\section{REFERÊNCIAS}

ALMEIDA. M. H. T. de. Recentralizando a Federação? Revista de Sociologia e Política, Curitiba, n. 24, p. 29-40, 2005.

ARANTES, B. C. Democracia, direito e política: uma análise da teoria da justiça de John Rawl. Revista da Procuradoria do Município de Juiz de Fora, Juiz de Fora, v. 1, p. 269-279, 2011.

ARAÚJO, M. V. R. de; TEIXEIRA, C. F. A participação dos atores na formulação da política de saúde da população negra na cidade de Salvador. Physis: Revista de Saúde Coletiva, Rio de Janeiro, v. 23, n. 4, p. 1079-1099, 2013.

ARRETCHE, M. Federalismo e relações intergovernamentais no Brasil: a reforma de programas sociais. Dados (Rio de Janeiro. Impresso), Rio de Janeiro, v. 45, n.3, p. 431-457, 2002.

ARRETCHE, M. Democracia, federalismo e centralização no Brasil. Rio de Janeiro: FGV/Editora Fiocruz, 2012.

ARRETCHE, M. Federalismo e políticas sociais no Brasil: problemas de coordenação e autonomia. São Paulo em Perspectiva, São Paulo, v. 18, n. 2, p. 17-26, 2004.

BASTOS, E. S. M. Avaliação da política de saúde integral da população negra no Municipio de Salvador. 2013. Dissertação (Mestrado em Políticas Sociais e Cidadania) - Universidade Católica do Salvador, Salvador, 2013.

BASTOS, E. S. M.; BITTENCOURT, L. de J. O Programa de Combate ao Racismo Institucional (PCRI) e a criação da Rede de Saúde da População Negra de Salvador: alguns elementos metodológicos. BIS: Boletim do Instituto de Saúde, São Paulo, v.12, n. 2, p. 179-184. ago. 2010. Disponível em: http://periodicos.ses.sp.bvs.br/scielo. php?script $=$ sci_arttext\&pid=S1518-18122010000200013\&lng=pt\&nrm=iss. Acesso em: 1 jul. 2015.

BATISTA, L. E.; WERNECK, J.; LOPES, F. Saúde da população negra. 2. ed. Brasília, DF: ABPN, 2012. (Negras e Negros: Pesquisas e Debates).

BRASIL. [Constituição (1988)]. Constituição da República Federativa do Brasil. Organização de Alexandre de Moraes. 16. ed. São Paulo: Atlas, 2000.

BRASIL, Ministério da Saúde. Secretaria de Gestão Estratégica e Participativa. Política Nacional de Saúde Integral da população negra. Brasília, DF: SEPPIR, 2007.

BRASIL, S. A. A política de saúde da população negra no Brasil: atores políticos, aspectos étnico-raciais e principais tensões do campo. 2011. Dissertação (Mestrado em Saúde Coletiva) - Universidade Federal da Bahia, Salvador, 2011.

BOURDIEU, P. O poder simbólico. 5. ed. Rio de Janeiro: Bertrand Brasil, 2002.

CARDOSO, M. O movimento negro. Belo Horizonte: Maza, 2002.

CARNEIRO, S. A batalha de Durban. Estudos Feministas, Florianópolis, ano1o, n.1, p.209-214, $1^{\circ}$ semestre 2002. 
CRI. Articulação para o combate ao racismo institucional. Identificação e abordagem do racismo institucional. Brasília: CRI, 2006.

CHOR, D.; LIMA, C. R. de A. Aspectos epidemiológicos das desigualdades raciais em saúde no Brasil. Cadernos de Saúde Pública, Rio de Janeiro, v. 21, n. 5, p. 1586-1594, 2005. Disponível em: http://www.scielo.br/pdf/csp/v21n5/33.pdf. Acesso em: 14 ago. 2014

DEUBEL, A.-N. R. Conceptos, teorias y herramientas para el análisis de las políticas públicas. In: DEUBEL, A.-N. R. Políticas públicas: formulación, implementación y evaluación. Bogotá: Ediciones Aurora, 2002. p. 17-56.

DOMINGUES, J. M. Os movimentos sociais latino-americanos: características e potencialidades. [S. l.]: Erscheinungsort nicht ermittelbar Análise de Conjuntura OPSA, 2007.

DOMINGUES, P. Movimento Negro Brasileiro: alguns apontamentos históricos. Tempo, Niterói, v. 12, n. 23, p. 100-122, 2006.

DRAIBE, S. M. A política social no período FHC e o sistema de proteção social. Tempo Social, São Paulo, v. 15, n. 2, nov. 2003.

FILGUEIRAS, F.; ARANHA, A. L. M. Controle da corrupção e burocracia da linha de frente: regras, discricionariedade e reformas no Brasil. Dados, Rio de Janeiro, v. 54, n. 2, p. 349-387, 2011.

GOMES, N. L. O movimento negro no Brasil: ausências, emergências e a produção dos saberes. Política e Sociedade, Florianópolis, v. 10, n. 18, p. 133-154, abr. 2011.

HILL, M. Implementação: uma visão geral. In: SARAVIA, E.; FERRAREZI, E. Políticas públicas. Brasília, DF: ENAP, 2006. v. 2, p. 61-90.

JACCOUD, L., BEGHIN, N. Desigualdades raciais no Brasil: um balanço da intervenção governamental. Brasília, DF: IPEA, 2002.

JACCOUD, L.; SILVA, A.; ROSA, W.; LUIZ, C. Entre o racismo e a desigualdade: da constituição à promoção de uma política de igualdade racial (1988-2008). In: Jaccoud, $\mathrm{L}$ (org.). A construção de uma política de promoção da igualdade racial: uma análise dos últimos 20 anos. Brasília, DF: Ipea, 2009. p. 19-92.

JONES, C. P. Levels of racism: a theoretic framework and a gardener's tale. American Journal of Public Health, Washington, v. 90, n. 8, p. 1212-1215, Aug. 2000.

LIMA, M. Desigualdades raciais e políticas públicas: ações afirmativas no governo Lula. Novos Estudos, São Paulo, n. 87, p. 77-95, jul. 2010. Disponível em: http://www.scielo.br/ pdf/nec/n87/a05n87.pdf. Acesso em: 6 ago. 2013.

LIPSKY, M. Street-level bureaucracy: dilemmas of the individual in public service. New York: Russell Sage Foundation, 2010.

LOPES, F. et al. (org.) Saúde da população negra no Brasil: contribuições para a promoção da eqüidade. Brasília, DF: Ministério da Saúde: Funasa, 2005. 
LOPEZ, L.C. O conceito de racismo institucional: aplicações no campo da saúde. Interface: Comunicação, Saúde, Educação, Botucatu, v. 16, n. 40, p.121-134, jan./mar. 2012. LOTTA, G. S. Desvendando o papel dos burocratas de nível de rua no processo de implementação: o caso dos agentes comunitários de saúde. In: FARIA, C. A. (org.). Implementação de políticas públicas: teoria e prática. Belo Horizonte: Editora PUC Minas, 2012b. p. 221-259.

LOTTA, G. S. Estilos de Implementação: ampliando o olhar para análise de políticas públicas. In: ENCONTRO NACIONAL DE ADMINISTRAÇÃO PÚBLICA E GOVERNANÇA, 2008, Salvador. Anais eletrônicos [...]. Salvador: ANPAD, 2008. Disponível em: http://www.anpad.org.br/admin/pdf/EnAPG208.pdf. Acesso em: 1 jul. 2015

LOTTA, G. S. Implementação de políticas públicas: o impacto dos fatores relacionais e organizacionais sobre os Burocratas de Nível de Rua no Programa Saúde da Família. 2010. Tese (Doutorado em Ciência Política) - Universidade de São Paulo, São Paulo, 2010.

LOTTA, G. S. O papel das burocracias do nível da rua na implementação de políticas públicas: entre o controle e a discricionariedade. In: FARIA, C. A. P. de. (org.). Implementação de políticas públicas: teoria e prática. Belo Horizonte: Editora PUC Minas, 2012a. p. 20-49.

LOTTA, G. S.; PAVEZ, T. R. Agentes de implementação: mediação, dinâmicas e estruturas relacionais. Cadernos Gestão Pública e Cidadania, São Paulo, v. 15, n. 56, 2010.

MENDES, E.V. 25 anos do Sistema Único de Saúde: resultados e desafios. Estudos Avançados, São Paulo, v. 27, n. 78, p. 27-34, 2013.

NUNES, E. A gramática política do Brasil: clientelismo, corporativismos e insulamento burocrático. Rio de Janeiro: Garamond, 2010.

OLIVEIRA, A. Burocratas da linha de frente: executores e fazedores das políticas públicas. Revista de Administração Pública, Rio de Janeiro, v. 46, n. 6, p. 1551-1573, 2012.

PAIM, J. S.; TEIXEIRA, C. F. Configuração institucional e gestão do Sistema Único e Saúde: problemas e desafios. Ciência \& Saúde Coletiva, Rio de Janeiro, v. 12, p. 1819-1829, 2007.

QUEIROZ, D. S. A discricionariedade da burocracia de rua no processo de implementação da Política de Saúde para a população negra em Salvador-BA. 2015. Dissertação (Mestrado em Ciências Sociais) - Universidade Federal da Bahia, Salvador, 2015.

QUEIROZ, D. S. A Política Nacional de Saúde para população negra em Salvador: incentivos e constrangimentos mapeados no processo de implementação. 2011. Trabalho de Conclusão de Curso (Graduação em Ciências Sociais) - Universidade Federal da Bahia, Salvador, 2012.

RAWLS, J. Uma teoria da justiça. Brasília, DF: Editora UnB, 1981. 
RACISMO institucional: uma abordagem conceitual. São Paulo: Geledés - Instituto da Mulher Negra, 2013.

RISÉRIO, A. A utopia brasileira e os movimentos negros. São Paulo: Editora 34, 2007.

SALVADOR. Secretaria Municipal de Saúde. Diagnóstico de saúde da população negra de Salvador. Salvador: Secretaria Municipal de Saúde, 2006.

SALVADOR. Secretaria Municipal de Saúde. Doença falciforme: manual para população. Salvador: Secretaria Municipal de Saúde, 2009.

SAMPAIO, E.O. Racismo institucional: desenvolvimento social e políticas públicas de caráter afirmativo no Brasil. Interações, Campo Grande, v. 4, n. 6, p. 77-83, 2003.

SANTOS, I. A. A. dos. Direitos humanos e a prática do racismo: o que faremos com os brancos racistas? 2009. Tese (Doutorado em Sociologia) - Universidade de Brasília, Brasília, DF, 2009.

SEMINÁRIO NACIONAL DE SAÚDE DA POPULAÇÃO NEGRA, 1, 2004, Brasília, DF. Caderno de textos básicos [...]. Brasília, DF: Secretaria Especial de Políticas de Promoção da Igualdade Racial, 2004.

SILVA, A. C. R. da. A racialização da saúde: (re)discutindo a relação natureza x cultura na construção de identidades étnicas/raciais. In: REUNIÃO BRASILEIRA DE ANTROPOLOGIA, 26., 2007, Porto Seguro. Anais [...]. Porto Seguro: [s. n.], 2007. p. 1-10.

SILVA, M.O.; FIGUEIREDO, N. D. de. Crítica sobre políticas, ações e programas de saúde implementados no Brasil. In: LOPES, F. et al. (org.). Saúde da população negra no Brasil: contribuições para a promoção da eqüidade. Brasília, DF: Ministério da Saúde: Funasa, 2004. p. 387-436.

SILVA, P. L. B.; MELO, M. A. B. de. O processo de implementação de políticas públicas no Brasil: características e determinantes da avaliação de programas e projetos. Campinas: UNICAMP, 2000. (Caderno, n. 48).

SILVA, R. M da C. A constituição de 1988 e a discriminação racial e de gênero no mercado de trabalho no Brasil. International Law: Revista Colombiana de Derecho Internacional, Bogotá, n. 23, p. 235-266, jul./dic. 2013.

SOUZA, C. Federalismo, desenho constitucional e instituições federativas no Brasil pós-1988. Revista de Sociologia e Política, Curitiba, n. 24, p. 105-121, jun. 2005.

SOUZA, C. Políticas públicas: uma revisão da literatura. Sociologias, Porto Alegre, ano 8 , n.16, p. 20-45, jul./dez. 2006.

SOUZA, J. Os batalhadores brasileiros: nova classe média ou nova classe trabalhadora? Belo Horizonte: Editora UFMG, 2010.

SOUZA, J. A modernização seletiva: uma reinterpretação do dilema brasileiro. Brasília, DF: Editora UnB, 2000. 
SOUZA, J. A parte de baixo da sociedade brasileira. Revista Interesse Nacional, São Paulo, v. 14, p. 33-41, 2011.

TEIXEIRA, C. F.; SOLLA, J. P. Modelo de atenção à saúde: promoção, vigilância e saúde da família. Salvador: EDUFBA, 2006. (Saladeaula, 3).

THEODORO, M. (org.). As políticas públicas e as desigualdades no Brasil: 120 anos após a abolição. Brasília, DF: Ipea, 2008.

TURE, K.; HAMILTON, C. V. Black power: the politics of liberation in America. New York: Vintage Books, 1992.

WERNECK, J. Iniquidades raciais em saúde e políticas de enfrentamento: experiências do Canadá, Estados Unidos, África do Sul e Reino Unido. In: LOPES, F. et al. (org.) Saúde da população negra no Brasil: contribuições para a promoção da eqüidade. Brasília, DF: Ministério da Saúde: Funasa, 2005, p. 315-386.

WIEVIORKA, M. O racismo, uma introdução. Tradução de Fany Kon. São Paulo: Perspectiva, 2007. 